\title{
Impact of surgical strategies on the survival of gallbladder cancer patients: analysis of 715 cases
}

\author{
Yigang Chang ${ }^{1,2}$, Qiang $\mathrm{Li}^{1 *}$, Qian $\mathrm{Wu}^{3}$, Limin $\mathrm{Chi}^{4}$, Xiaogang $\mathrm{Bi}^{2}$, Qingmin Zeng ${ }^{1,5}$ and Huaying Huo ${ }^{6}$
}

\begin{abstract}
Objective: The aim of the study is to evaluate the impact of application of surgical strategies at different cancer stages on the survival of gallbladder cancer (GBC) patients.

Methods: The patients with GBC were divided into 3 groups according to their received surgical strategies: simple resection (full-thickness cholecystectomy for removal of primary tumor site), radical resection (gallbladder bed removal combined with partial hepatectomy), and palliative surgery (treatment at advanced stages). The overall survival (OS) of GBC patients who were received different surgical strategies was compared.

Results: Survival analysis showed that radical resection had a best OS at clinical stage II, and simple resection had a best OS at tumor clinical stage IV. Cox hazard proportional regression analysis showed that more advanced tumor stages, tumor location of gallbladder body or neck, and CA199 $\geq 27 \mathrm{U} / \mathrm{mL}$ were the major risk factors for the OS of GBC.

Conclusions: At tumor stage II, radical resection should be the most effective surgical therapy for GBC. However, the effect of radical resection at advanced stages could be restricted. The utilization of radical resection should be increased at tumor stage II for a better long-term survival outcome.
\end{abstract}

Keywords: Gallbladder cancer, Surgical strategy, Survival analysis, Radical surgery, Palliative surgery

\section{Introduction}

According to the Global Cancer Statistics 2018, gallbladder cancer (GBC) caused an estimated 219,420 new cases and 165,087 new deaths worldwide in the year 2018 [1]. The incidence and mortality of GBC is much higher in developing countries or areas, such as India, Valdivia, Chile, South America, Pakistan, Eastern Europe, and China, than that in developed countries [2]. As the most common cancer type of biliary tract cancer, $70 \%$ of $\mathrm{GBC}$ are incidentally diagnosed after a routine

\footnotetext{
* Correspondence: qiangli_|@aliyun.com

'Department of Hepatobiliary Surgery, Tianjin Medical University Cancer Institute and Hospital, National Clinical Research Center for Cancer \& Key Laboratory of Cancer Prevention and Therapy, Tianjin, Tianjin's Clinical Research Center for Cancer, Tianjin 300060, China

Full list of author information is available at the end of the article
}

cholecystectomy for a benign disease [3]. Due to the lack of specific protocol for clinic diagnosis in early stages, GBC is usually found at advanced stages [4]. The outcome of GBC is poor, with a less than $5 \%$ of overall 5year survival; however, $75 \%$ of overall 5 -year survival can be achieved if the cancer is detected at an early stage [5]. Multiple factors, including environment, diagnosis, tumor stages, treatment options, and other complications, can impact the survival outcome of GBC patients [6-8].

Guidelines for $\mathrm{GBC}$ radical resection vary in different countries [9]. Goetze et al. have demonstrated the effective of radical resection for incidental GBC [5]. However, as an important treatment strategy of GBC, radical resection is underutilized in practice $[10,11]$. According 
to the Chinese Guidelines for $\mathrm{GBC}$, the surgical treatment is suggested based on the TNM staging: simple cholecystectomy is recommended in patients with a tumor at Tis or T1a stage; radical resection is recommended in patients with stage T1b or T2; palliative treatment is suggested in patients at $\mathrm{T} 3$ or T4 stage. The suggested treatment of radical resection for GBC is wedge resection of the gallbladder bed with no less than $2 \mathrm{~cm}$ margin in the liver, a resection of liver segments $4 \mathrm{~b}$ and 5, or a resection of the right liver, which is combined with dissection of the regional lymph nodes. For advanced stages of GBC, palliative treatment, such as palliative cholecystectomy, percutaneous transhepatic cholangial drainage (PTCD), percutaneous transhepatic biliary drainage (PTBD), and gallbladder bypass, is also recommended. Since liver resection has been verified to have a poor survival outcome, with a 13 18\% in-hospital mortality, $[12,13]$, the effect of radical surgery for GBC patients at advanced stages with poor conditions is quite limited. Kawahara et al. also have reported an effective surgical strategy for extent of resection in GBC at T2 stage, which is based on the gallbladder location of tumor [14].

Full-thickness cholecystectomy, radical resection surgery, and palliative surgery are the major surgical strategies for GBC at present. Few studies have systematically compared the application of different surgical strategies for GBC. Here, we aimed to analyze the OS of 715 GBC patients who have received fullthickness cholecystectomy, radical resection surgery, or palliative surgery and investigate the impact of strategy of surgery on the long-term survival in GBC patients at different tumor stages.

\section{Methods}

\section{Patients}

All patients with $\mathrm{GBC}$ in the present study received antitumor treatment in the Tianjin Medical University Cancer Institute and Hospital, the Shanxi Provincial People's Hospital, the Shanxi Tumor Hospital, or the First Hospital of Shanxi Medical University from 2012 to 2017. The initial symptoms of the cancer patients mainly include abdominal discomfort $(\sim 50 \%)$ and jaundice $(\sim$ $28 \%$ ), and about $14 \%$ patients were detected by physical examination as well. Then, the patients were further diagnosed by B-ultrasound (BUS), computed tomography (CT), pathology, and magnetic resonance imaging (MRI). All patients were staged according to the 8th edition of the AJCC/UICC classification in 2017 [15]. Patients accompanied with other malignant tumor, patients without determined clinical pathology, patients with recurring GBC, and patients without surgical treatment were excluded. Patients were divided into three groups according to the strategies of surgical treatment received: simple resection, radical resection, and palliative surgery. Simple resection was defined as "partial or total resection of primary tumor site," and radical resection was defined as "total resection of primary tumor site with other organs"; palliative surgery was performed in patients with distant metastases cancer, wide tumor invasion, and conditions wherein they cannot bear aggressive surgery or they refuse.

\section{Demographics and clinicopathological information of patients}

A total of 715 patients were recruited in the study. Demographics (source, age, gender, and BMI) and clinicopathological (tumor grade, clinical staging, TNM stage, gallbladder location of tumor, smoking or not, CA199, CA242, with chronic disease or gallstone or not, adjuvant therapy, strategy of surgery) information of the GBC patients were collected for the analysis. Gallbladder location of tumor was grouped as follows: fundus of the gallbladder, body of the gallbladder, and neck of the gallbladder or unknown. Involved chronic diseases mainly included diabetes, hypertension, and coronary heart disease. The adjuvant therapy mainly included radiotherapy, chemotherapy, and biotherapy.

\section{Statistical analysis}

All data in present study were analyzed using MedCalc Statistical Software version 15.2.2 (MedCalc Software bvba, Ostend, Belgium). Discrete variables were presented as number and percentage. Statistical difference analysis in baseline characteristics was performed using chi-squared $\left(\chi^{2}\right)$ test. Overall survival (OS) curves for GBC patients were assessed using Kaplan-Meier survival method, and the Logrank test was used to compare the difference between subgroups. Univariate and multivariate Cox proportional hazards regression analysis was performed to reveal the risks factors for GBC survival outcomes. $p<0.05$ indicates statistically significant difference.

\section{Results}

\section{Population and characteristics of the GBC patients}

There were a total of 1146 cases of diagnosed GBC from 2012 to 2017. Three hundred ninety-three cases were excluded for undergoing no surgery or an unknown surgery, 18 cases were excluded for recurrence of primary GBC, and 20 cases were excluded for suffering with other types of cancer. Of the enrolled 715 cases, 126 (17.5\%) cases received simple resection, 349 (48.8\%) cases underwent radical resection, and 240 (35.6\%) cases were treated with palliative surgery. Patients' general and clinicopathologic information were shown in Table 1. The median age of the patients was 62 years $(\mathrm{min} / \mathrm{max}$ age $=29 / 88$ years). Two hundred fifty-eight $(36.1 \%)$ 
Table 1 General, clinicopathologic, treatment, and follow-up characteristics for the 715 gallbladder cancer patients with different surgery treatments

\begin{tabular}{|c|c|c|c|c|c|}
\hline Variates & $\begin{array}{l}\text { Total } \\
(n=715) N(\%)\end{array}$ & $\begin{array}{l}\text { Simple resection } \\
(n=126) N(\%)\end{array}$ & $\begin{array}{l}\text { Radical resection } \\
(n=349) N(\%)\end{array}$ & $\begin{array}{l}\text { Palliative surgery } \\
(n=240) N(\%)\end{array}$ & $p$ \\
\hline Sources & & & & & 0.2488 \\
\hline Urban & $299(41.8)$ & $56(44.4)$ & $153(43.8)$ & $90(37.5)$ & \\
\hline Country & $416(58.2)$ & 70 (55.6) & $196(56.2)$ & $150(62.5)$ & \\
\hline Ages (years) & & & & & 0.0198 \\
\hline$<60$ & $275(38.5)$ & $41(32.5)$ & $154(44.1)$ & 80 (33.3) & \\
\hline $60-69$ & $264(36.9)$ & $48(38.1)$ & $125(35.8)$ & 91 (37.9) & \\
\hline$\geq 70$ & $176(24.6)$ & $37(29.4)$ & $70(20.1)$ & 69 (28.8) & \\
\hline Sex & & & & & 0.0573 \\
\hline Female & $258(36.1)$ & $34(27)$ & $130(37.2)$ & 94 (39.2) & \\
\hline Male & 457 (63.9) & $92(73)$ & $219(62.8)$ & $146(60.8)$ & \\
\hline BMI $\left(\mathrm{Kg} / \mathrm{m}^{2}\right)$ & & & & & 0.293 \\
\hline$<28$ & $613(85.7)$ & $109(86.5)$ & 301 (86.2) & $203(84.6)$ & \\
\hline$\geq 28$ & 80 (11.2) & $10(7.9)$ & 39 (11.2) & 31 (12.9) & \\
\hline Unknown & $22(3.1)$ & $7(5.6)$ & $9(2.6)$ & $6(2.5)$ & \\
\hline Smoking history & & & & & 0.3083 \\
\hline No & $568(79.4)$ & $105(83.3)$ & $279(80)$ & $184(76.7)$ & \\
\hline Yes & 147 (20.6) & $21(16.7)$ & $70(20)$ & $56(23.3)$ & \\
\hline Gallbladder location of tumor & & & & & $<0.0001$ \\
\hline Fundus & $208(29.1)$ & $45(35.7)$ & $123(35.2)$ & $40(16.7)$ & \\
\hline Body & $321(44.9)$ & $62(49.2)$ & $151(43.3)$ & $108(45)$ & \\
\hline Neck & $150(21)$ & $19(15.1)$ & $75(21.5)$ & $56(23.3)$ & \\
\hline Unknown & $36(5)$ & 0 & 0 & $36(15)$ & \\
\hline Clinical staging & & & & & $<0.0001$ \\
\hline । & $35(4.9)$ & $20(15.9)$ & $15(4.3)$ & 0 & \\
\hline$\|$ & $82(11.5)$ & $37(29.4)$ & 45 (12.9) & 0 & \\
\hline III & $291(40.7)$ & $59(46.8)$ & $214(61.3)$ & $18(7.5)$ & \\
\hline IV & 307 (42.9) & $10(7.9)$ & $75(21.5)$ & $222(92.5)$ & \\
\hline T stage & & & & & $<0.0001$ \\
\hline T1 & $34(4.8)$ & $16(12.7)$ & $18(5.2)$ & 0 & \\
\hline $\mathrm{T} 2$ & $92(12.9)$ & $38(30.2)$ & $53(15.2)$ & $1(0.4)$ & \\
\hline T3 & $381(53.3)$ & $64(50.8)$ & $255(73.1)$ & $62(25.8)$ & \\
\hline T4 & $125(17.5)$ & $4(3.2)$ & $22(6.3)$ & 99 (41.3) & \\
\hline Unknown & $83(11.6)$ & $4(3.2)$ & $1(0.3)$ & 78 (32.5) & \\
\hline N stage & & & & & $<0.0001$ \\
\hline NO & 276 (38.6) & 70 (55.6) & $197(56.4)$ & $9(3.8)$ & \\
\hline N1 & 88 (12.3) & $5(4)$ & 77 (22.1) & $6(2.5)$ & \\
\hline N2 & 90 (12.6) & $3(2.4)$ & 58 (16.6) & $29(12.1)$ & \\
\hline Unknown & $211(29.5)$ & $48(38.1)$ & $17(4.9)$ & $146(60.8)$ & \\
\hline M stage & & & & & $<0.0001$ \\
\hline MO & $524(73.3)$ & $119(94.4)$ & 338 (96.8) & 67 (27.9) & \\
\hline M1 & $158(22.1)$ & $6(4.8)$ & $8(2.3)$ & $144(60)$ & \\
\hline Unknown & $33(4.6)$ & $1(0.8)$ & $3(0.9)$ & $29(12.1)$ & \\
\hline
\end{tabular}


Table 1 General, clinicopathologic, treatment, and follow-up characteristics for the 715 gallbladder cancer patients with different surgery treatments (Continued)

\begin{tabular}{|c|c|c|c|c|c|}
\hline Variates & $\begin{array}{l}\text { Total } \\
(n=715) N(\%)\end{array}$ & $\begin{array}{l}\text { Simple resection } \\
(n=126) N(\%)\end{array}$ & $\begin{array}{l}\text { Radical resection } \\
(n=349) N(\%)\end{array}$ & $\begin{array}{l}\text { Palliative surgery } \\
(n=240) N(\%)\end{array}$ & $p$ \\
\hline Grade & & & & & $<0.0001$ \\
\hline Well-differentiated & $27(3.8)$ & $13(10.3)$ & $11(3.2)$ & $3(1.3)$ & \\
\hline Moderately differentiated & $112(15.7)$ & $30(23.8)$ & $73(20.9)$ & $9(3.8)$ & \\
\hline Poorly differentiated & $184(25.7)$ & $28(22.2)$ & $122(35)$ & $34(14.2)$ & \\
\hline Unknown & $392(54.8)$ & $55(43.7)$ & $143(41)$ & $194(80.8)$ & \\
\hline CA199 & & & & & 0.0266 \\
\hline$<27 \mathrm{U} / \mathrm{mL}$ & $262(36.6)$ & $59(46.8)$ & $168(53.2)$ & 35 (14.6) & \\
\hline$\geq 27 \mathrm{U} / \mathrm{mL}$ & $388(54.3)$ & 49 (38.9) & $158(45.3)$ & $181(75.4)$ & \\
\hline Unknown & $65(9.1)$ & $18(14.3)$ & $23(6.6)$ & $24(10)$ & \\
\hline \multicolumn{6}{|l|}{ CA242 } \\
\hline$<20 \mathrm{IU} / \mathrm{mL}$ & $296(41.4)$ & $61(48.4)$ & $171(49)$ & $64(26.7)$ & $<0.0001$ \\
\hline$\geq 20 \mathrm{IU} / \mathrm{mL}$ & $311(43.5)$ & $33(26.2)$ & $131(37.5)$ & $147(61.3)$ & \\
\hline Unknown & $108(15.1)$ & $32(25.4)$ & $47(23.5)$ & $29(12.1)$ & \\
\hline With chronic disease & & & & & 0.2935 \\
\hline No & $433(60.6)$ & $74(58.7)$ & $204(58.5)$ & $155(64.6)$ & \\
\hline Yes & $282(39.4)$ & $52(41.3)$ & $145(41.5)$ & $85(35.4)$ & \\
\hline Gallstone & & & & & $<0.0001$ \\
\hline No & $321(44.9)$ & $34(27)$ & $162(46.4)$ & $125(52.1)$ & \\
\hline Yes & $394(55.1)$ & $92(73.1)$ & $187(53.6)$ & $115(47.9)$ & \\
\hline Adjuvant therapy & & & & & $<0.0001$ \\
\hline None & $537(75.1)$ & $96(76.2)$ & $239(68.5)$ & $202(84.2)$ & \\
\hline Received & $178(24.9)$ & $30(23.8)$ & $110(31.5)$ & $38(15.8)$ & \\
\hline \multicolumn{6}{|l|}{ Follow-up } \\
\hline Alive & $212(29.7)$ & $59(46.8)$ & $136(39)$ & $17(7.1)$ & \\
\hline 3-year survival & $254(35.5)$ & $69(54.8)$ & $134(38.4)$ & $51(21.3)$ & \\
\hline Months, median(95\% Cl) & $27(22-31)$ & $51(41-69)$ & $34(28-44)$ & $10(7-14)$ & \\
\hline
\end{tabular}

Results are number (\%) unless otherwise specified

females and 457 (63.9\%) males were included in the recruited population. Two hundred ninety-nine (41.8\%) patients were from the urban, and 416 (58.2\%) patients were from the country.

\section{Association between the characteristic factors and surgical strategies}

Chi-squared $\left(\chi^{2}\right)$ analysis showed that there was a significant difference among the three groups including ages $(p<0.05)$, gallbladder location of tumor $(p<0.0001)$, clinical staging $(p<0.0001)$, TNM stage $(p<0.0001)$, tumor grade $(p<0.0001)$, CA199 $(p<0.05)$, CA242 $(p<$ $0.0001)$, gallstone $(p<0.0001)$, and adjuvant therapy ( $p$ $<0.0001)$. In detail, patients with tumor location not in gallbladder neck, earlier clinical staging (I/II), T1/T2 stage, normal level of tumor markers, and gallstone were more likely to undergo simple resection. Patients with young age, N1/N2 stage, and poorly differentiated tumor were more likely to receive radical resection. Patients with M1 stage, CA199 $\geq 27 \mathrm{U} / \mathrm{ml}$, CA242 $\geq 20 \mathrm{IU} / \mathrm{ml}$, and unreceived adjuvant therapy were more likely to receive palliative surgery.

\section{The impact of surgical strategies on OS of patients}

The median OS time of the 715 patients was 24 months (95\% CI 22-28 months). Kaplan-Meier survival analysis was performed to measure OS with different clinical stages and different surgical strategies, respectively (Fig. 1). Form stage I to IV cases, the survival rate were $85.71 \%, 64.63 \%, 36.08 \%$, and $10.42 \%$ (Fig. 1a). As shown in Fig. 1b, compared with the palliative surgery groups, patients with simple resection or radical resection had significant longer OS time $(p<0.0001)$. Patients with simple resection had the best OS outcome, with a 


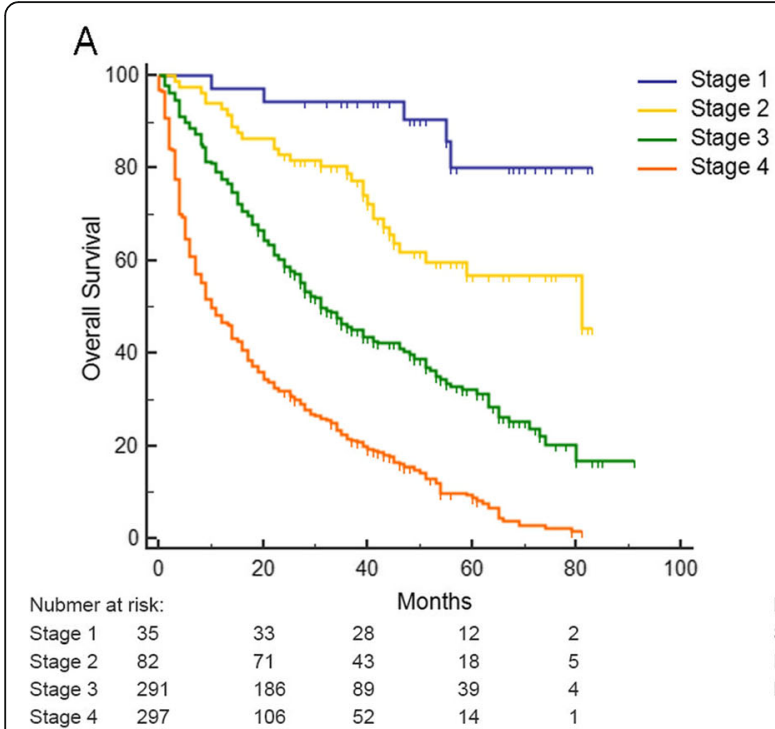

B

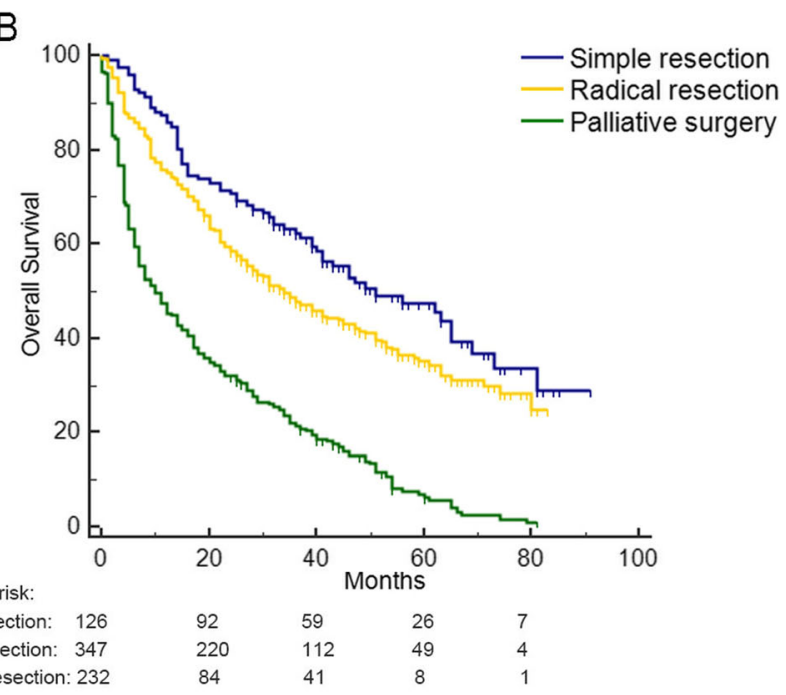

Fig. 1 Overall survival (OS) for GBC according to stages and surgical strategies. a Kaplan-Meier survival analysis was used to compare OS among patients with different cancer stages $(p<0.0001)$. b Kaplan-Meier survival analysis was used to compare OS of patients received with different surgical strategies $(p<0.0001)$

$47.62 \%$ of survival rate and 51 months of median OS time (95\% CI 41-69 months). The OS outcome of patients with radical resection was moderate, with a $39.83 \%$ of survival rate and 34 months of median overall survival time (95\% CI $28-44$ months). The palliative surgery patient group had the worst OS outcome, with an $8.75 \%$ of survival rate and 10 months of median OS time (95\% CI 7-14 months).

Furthermore, the effect of the surgical strategies on different cancer clinical stages were explored. The difference of OS between simple resection and radical resection in stage I patients was not significant ( $p=0.9344$, Fig. 2a). However, patients with radical resection had a better OS than patients with simple resection at stage II $(p=0.0415$, Fig. 2b). Compared with simple resection and radical resection groups, patients with palliative surgery had a worse overall survival at cancer stage III $(p=$ 0.0275, Fig. 2c). At cancer stage IV, patients with simple resection also had a best overall survival $(p=0.0129$, Fig. 2d).

\section{The risk factors associated with the OS}

Univariate and multivariate Cox proportional hazards regression model was established to evaluate the hazard ratio (HR) of variates (Table 2). Univariate analysis showed that patients from the countryside, with tumor location of gallbladder body or neck, with increased tumor stages, with increased TNM stages, with poorly differentiated of the tumor, with CA199 $\geq 27 \mathrm{U} / \mathrm{mL}$, with $\mathrm{CA} 242 \geq 20 \mathrm{IU} / \mathrm{mL}$, and with surgical treatment of radical resection or palliative surgery were related to a worse long-term survival of GBC. Multivariate analysis showed that the tumor location of gallbladder body or neck $(\mathrm{HR}=1.4901,95 \% \mathrm{CI}=1.1858$ to $1.8726, p=$ 0.007), more advanced tumor stages, and CA199 $\geq 27 \mathrm{U} /$ $\mathrm{mL}(\mathrm{HR}=1.3941,95 \% \mathrm{CI}=1.0838$ to $1.7933, p=$ 0.0101 ) might be the main causes for induction a worse long-term survival of $\mathrm{GBC}$, and the surgical strategies of radical resection $(\mathrm{HR}=1.0397,95 \% \mathrm{CI}=0.7820$ to $1.3823, p=0.7898)$ or palliative surgery $(\mathrm{HR}=1.41,95 \%$ $\mathrm{CI}=0.9886$ to $2.0111, p=0.0592$ ) were not associated with OS.

\section{Discussion}

GBC is an uncommon cancer type with a high mortality rate and poor long-term survival outcomes [16]. Surgical treatment is the most effective intervention for the cure of GBC patients [17]; however, curative resection is feasible in minority population of GBC patients [18]. According to the Guidelines of the National Comprehensive Cancer Network, a radical resection is recommended for T1b and more advanced GBC [19]. Actually, the option for surgical strategies should be confirmed according to both the patients' conditions and tumor clinicopathology characteristics [20]. On the other hand, Goetze et al. have reported the phenomenon of that compared with following the guidelines; the application of radical resection for incidental GBC much more depend on the volume of clinical liver surgery in Germany [9]. Thus, we suspected that the options of surgery strategies in GBC patients may affect the overall survival outcomes of cancer.

In the present study, the surgical strategies for GBC were divided into 3 subgroups, including simple 


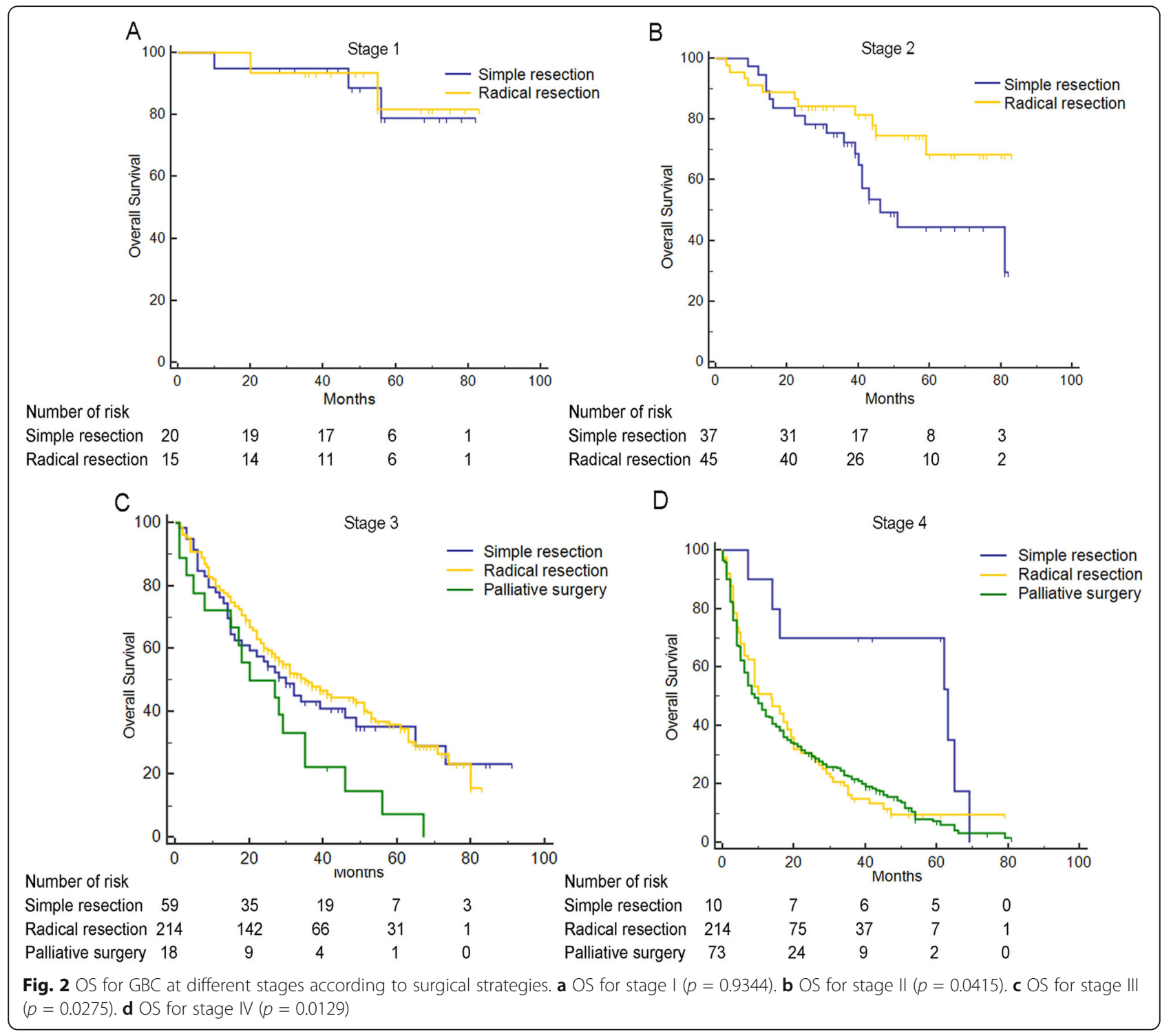

resection, radical resection, and palliative surgery. Among these investigated categories, we found that ages, tumor clinical stages, TNM stages, tumor grade, gallbladder location of tumor, tumor markers (CA199 and CA242), gallstone, and adjuvant therapy were the influencing factors for surgery strategies. Patients with earlier tumor clinical stage, earlier $\mathrm{T}$ stage, tumor location not in gallbladder neck, normal level of tumor markers, and gallstone were more associated with simple resection. Analogously, a study in 87 GBC patients by Wang et al. has reported that the levels of tumor markers (CA199, CA125, and CA242) in patients with tumor in gallbladder neck were much higher than in those with tumor in gallbladder fundus and body [21]. Patients with young ages, N1/N2 stage, and poorly differentiated were more associated with radical resection. It has been proved that liver resection is related to a high mortality rate, and young age would play a protective role for patients with radical resection in perioperative period. Patients with advanced tumor stages, high levels of tumor markers (CA199, CA242), metastatic cancer (M1), and adjuvant therapy unreceived were more associated with palliative surgery. For the metastatic cancer and surgery inoperable patient, palliative surgery would be the treatment for relieving the patient's pain and promoting patients' quality of life.

As our before results, surgical strategies were closely associated with the tumor stages, and the long-term survival outcome of GBC patients is distinguished according to the stage-adjusted surgical strategies (Fig. 1b). Plenty of studies have indicated that the performance of radical resection might be the best choice for GBC management at clinical stage II [14, 17, 22-25]. In our study, we also found that radical resection should be the only 
Table 2 Cox proportional hazards regression analysis for OS

\begin{tabular}{|c|c|c|c|c|c|c|}
\hline \multirow[t]{2}{*}{ Variates } & \multicolumn{3}{|c|}{ Univariate analysis } & \multicolumn{3}{|c|}{ Multivariate analysis } \\
\hline & $\overline{\mathrm{HR}}$ & $95 \% \mathrm{Cl}$ & $p$ & $\overline{\mathrm{HR}}$ & $95 \% \mathrm{Cl}$ & $p$ \\
\hline \multicolumn{7}{|l|}{ Sources } \\
\hline Urban & Ref & Ref & Ref & Ref & Ref & Ref \\
\hline Country & 1.221 & $1.0212-1.4598$ & 0.0293 & 1.0272 & $0.8533-1.2364$ & 0.7779 \\
\hline Ages (years) & & & & & & $\mathrm{Nl}$ \\
\hline$<60$ & Ref & Ref & Ref & & & \\
\hline $60-69$ & 0.9238 & $0.7541-1.1316$ & 0.4461 & & & \\
\hline$\geq 70$ & 1.0349 & $0.8269-1.2952$ & 0.08909 & & & \\
\hline Sex & & & & & & $\mathrm{NI}$ \\
\hline Female & Ref & Ref & Ref & & & \\
\hline Male & 0.883 & $0.7374-1.0573$ & 0.1781 & & & \\
\hline $\mathrm{BMI}\left(\mathrm{Kg} / \mathrm{m}^{2}\right)$ & & & & & & $\mathrm{NI}$ \\
\hline$<28$ & Ref & Ref & Ref & & & \\
\hline$\geq 28$ & 1.1157 & $0.8557-1.4548$ & 0.4211 & & & \\
\hline Unknown & 0.4844 & $0.2595-0.9043$ & 0.0236 & & & \\
\hline Smoking history & & & & & & $\mathrm{NI}$ \\
\hline No & Ref & Ref & Ref & & & \\
\hline Yes & 1.0663 & $0.8604-1.3215$ & 0.5596 & & & \\
\hline \multicolumn{7}{|c|}{ Gallbladder location of tumor } \\
\hline Fundus & Ref & Ref & Ref & Ref & Ref & Ref \\
\hline Body & 1.5472 & $1.2442-1.9241$ & 0.0001 & 1.4901 & $1.1858-1.8726$ & 0.0007 \\
\hline Neck & 1.4257 & $1.0976-1.8519$ & 0.0082 & 1.1776 & $0.8959-1.5479$ & 0.2437 \\
\hline Unknown & 1.445 & $0.9751-2.1412$ & 0.068 & 0.6761 & $0.4434-1.0310$ & 0.0705 \\
\hline \multicolumn{7}{|l|}{ Clinical staging } \\
\hline I & Ref & Ref & Ref & Ref & Ref & Ref \\
\hline$\|$ & 2.9912 & $1.1632-7.6921$ & 0.0237 & 2.9253 & $1.1281-7.5861$ & 0.0281 \\
\hline III & 7.3437 & $3.0318-17.7882$ & $<0.0001$ & 6.4359 & $2.6198-15.8108$ & 0.0001 \\
\hline IV & 16.4044 & $6.7898-39.6340$ & $<0.0001$ & 10.4364 & $4.1505-26.2422$ & $<0.0001$ \\
\hline T stage & & & & & & $\mathrm{Nl}$ \\
\hline $\mathrm{T} 1$ & Ref & Ref & Ref & & & \\
\hline $\mathrm{T} 2$ & 2.2162 & $0.9901-4.9607$ & 0.0541 & & & \\
\hline T3 & 5.6811 & $2.6900-11.9979$ & $<0.0001$ & & & \\
\hline $\mathrm{T} 4$ & 9.2513 & $4.3199-19.8121$ & $<0.0001$ & & & \\
\hline Unknown & 12.0606 & $5.5666-26.1303$ & $<0.0001$ & & & \\
\hline N stage & & & & & & $\mathrm{NI}$ \\
\hline No & Ref & Ref & Ref & & & \\
\hline N1 & 2.4167 & $1.7968-3.2505$ & 0.017 & & & \\
\hline $\mathrm{N} 2$ & 4.2985 & $3.2423-5.6989$ & $<0.0001$ & & & \\
\hline Unknown & 3.1367 & $2.5164-3.9099$ & $<0.0001$ & & & \\
\hline M stage & & & & & & $\mathrm{NI}$ \\
\hline MO & Ref & Ref & Ref & & & \\
\hline M1 & 2.4876 & $2.0433-3.0286$ & $<0.0001$ & & & \\
\hline Unknown & 1.4786 & $1.0065-2.1721$ & 0.0474 & & & \\
\hline
\end{tabular}


Table 2 Cox proportional hazards regression analysis for OS (Continued)

\begin{tabular}{|c|c|c|c|c|c|c|}
\hline \multirow[t]{2}{*}{ Variates } & \multicolumn{3}{|c|}{ Univariate analysis } & \multicolumn{3}{|c|}{ Multivariate analysis } \\
\hline & $\mathrm{HR}$ & $95 \% \mathrm{Cl}$ & $p$ & $\mathrm{HR}$ & $95 \% \mathrm{Cl}$ & $p$ \\
\hline Well-differentiated & Ref & Ref & Ref & Ref & Ref & Ref \\
\hline Moderately differentiated & 1.4133 & $0.7651-2.6107$ & 0.2717 & 1.3022 & $0.6944-2.4420$ & 0.4128 \\
\hline Poorly differentiated & 2.3874 & $1.3269-4.2957$ & 0.0039 & 1.7171 & $0.9330-3.1604$ & 0.0839 \\
\hline Unknown & 2.4023 & $1.3517-4.2694$ & 0.003 & 1.5552 & $0.8560-2.8257$ & 0.1493 \\
\hline \multicolumn{7}{|l|}{ CA199 } \\
\hline$<27 \mathrm{U} / \mathrm{mL}$ & Ref & Ref & Ref & Ref & Ref & Ref \\
\hline$\geq 27 \mathrm{U} / \mathrm{mL}$ & 2.2785 & $1.8655-2.7830$ & $<0.0001$ & 1.3941 & $1.0838-1.7933$ & 0.0101 \\
\hline Unknown & 1.3304 & $0.9374-1.8881$ & 0.1118 & 1.2309 & $0.6981-2.1705$ & 0.475 \\
\hline \multicolumn{7}{|l|}{ CA242 } \\
\hline$<20 \mathrm{IU} / \mathrm{mL}$ & Ref & Ref & Ref & Ref & Ref & Ref \\
\hline$\geq 20 \mathrm{IU} / \mathrm{mL}$ & 1.9779 & $1.6322-2.3969$ & $<0.0001$ & 1.1169 & $0.8790-1.4192$ & 0.3679 \\
\hline Unknown & 1.042 & $0.7776-1.3964$ & 0.7838 & 1.0146 & $0.6312-1.6310$ & 0.9525 \\
\hline With chronic disease & & & & & & $\mathrm{NI}$ \\
\hline No & Ref & Ref & Ref & & & \\
\hline Yes & 0.8733 & $0.7292-1.0460$ & 0.1432 & & & \\
\hline Gallstone & & & & & & $\mathrm{NI}$ \\
\hline No & Ref & Ref & Ref & & & \\
\hline Yes & 0.9403 & $0.7885-1.1213$ & 0.4955 & & & \\
\hline Adjuvant therapy & & & & & & $\mathrm{NI}$ \\
\hline None & Ref & Ref & Ref & & & \\
\hline Received & 0.8719 & $0.7105-1.0699$ & 0.1916 & & & \\
\hline \multicolumn{7}{|l|}{ Surgery } \\
\hline Simple resection & Ref & Ref & Ref & Ref & Ref & Ref \\
\hline Radical resection & 1.3679 & $1.0384-1.8021$ & 0.0267 & 1.0397 & $0.7820-1.3823$ & 0.7898 \\
\hline Palliative surgery & 3.3214 & $2.5191-4.3792$ & $<0.0001$ & 1.41 & $0.9886-2.0111$ & 0.0592 \\
\hline
\end{tabular}

Ref reference, $\mathrm{Cl}$ confidence interval, $\mathrm{N} /$ not included in the multivariate survival analysis

reliable and safe surgical therapy for GBC patients with stage II (Fig. 2b). However, a high mortality rate within about 12 months after surgery might be one of the primary limitations for the utilization of radical surgery at stage II. At advanced stages, compared with simple resection or palliative surgery, the effect of radical surgery on overall survival was obviously decreased (Fig. 2c, d). Previous studies have assessed the efficiency of radical surgery at stages III and IV, with a 25 to $50 \% 5$-year survival $[17,26,27]$. However, the comparison among different surgical strategies at advanced stages is rare. In current study, there is no significant difference in 5-year survival at stage III between radical resection and simple resection groups, but palliative surgery groups had a lowest overall survival. Thus, aggressive resection is still an effective therapy at stage III, even if it is available in partial individuals. The application of radical resection in stage IV patients is controversial. In our study, we also found that the difference of overall survival at stage IV between radical resection and palliative surgery groups was not significant (Fig. 2d). Also, it seemed that the simple resection groups had a good performance for overall survival at stage IV; however, the subgroup size was too small to summarize a reliable conclusion.

At present, the prognosis of GBC mainly depends on the tumor stages [22]. The Cox hazard proportional regression analysis showed that advanced tumor stages, high levels of CA199, and tumor location in gallbladder body or neck would indicate a poor prognosis. Studies have reported that CA199 is a prognosis related marker $[21,28,29]$. Moreover, Wang et al. have reported that tumor location in gallbladder neck could be a prognosisrelated marker [21]. Compared with aggressive resection, palliative surgery groups would have a worse prognosis $(\mathrm{HR}=1.41,95 \% \mathrm{CI}=0.9886$ to $2.0111, p=0.0592)$.

However, there were some limitations in our study. In the investigated population, more than $70 \%$ of them were patients with advanced cancer, in which the effect of surgical treatment is quite limited. Also, since the outcome for advanced GBC is poor, the willingness of 
patients with cancer at stage IV for aggressive therapy is usually wobbly, which may impact the strategic choice for surgery to a large extent. On the other hand, the surveyed sample size was limited; the long-term survival come for GBC could be affected by composite factors [ 6 , $30,31]$.

In conclusion, the overall survival for GBC mainly depends on the stages of detected tumor; however, aggressive surgery could be always the reasonable surgical therapy for patients with GBC, especially, and radical resection could be a most effective surgical strategy for patients with tumor at stage II to obtain a long-term survival. Additionally, our report supports the viewpoint that the role of radical resection in advanced stages is restricted, but, in early stage, the utilization of radical surgery should be further developed.

\section{Acknowledgements}

None

\section{Authors' contributions}

Guarantor of integrity of the entire study: Qiang Li. Study concepts: Yigang Chang. Study design: Yigang Chang. Definition of intellectual content: Yigang Chang. Literature research: Yigang Chang. Clinical studies: Yigang Chang, Xiaogang Bi. Experimental studies: Yigang Chang. Data acquisition: Yigang Chang, Qian Wu, Limin Chi. Data analysis: Yigang Chang, Qingmin Zeng, Huaying Huo. Statistical analysis: Yigang Chang. Manuscript preparation: Yigang Chang. Manuscript editing: Yigang Chang. Manuscript review: Qiang Li. The authors read and approved the final manuscript.

\section{Funding}

None

\section{Availability of data and materials}

The datasets used or analyzed during the current study are available from the corresponding author on reasonable request.

\section{Ethics approval and consent to participate}

All procedures performed in studies involving human participants were in accordance with the ethical standards of the institutional and/or national research committee and with the 1964 Helsinki declaration and its later amendments or comparable ethical standards. This study is approved by Ethics Committee of Tianjin Medical University Cancer Institute and Hospital.

\section{Consent for publication}

It is unavailable.

\section{Competing interests}

None

\section{Author details}

${ }^{1}$ Department of Hepatobiliary Surgery, Tianjin Medical University Cancer Institute and Hospital, National Clinical Research Center for Cancer \& Key Laboratory of Cancer Prevention and Therapy, Tianjin, Tianjin's Clinical Research Center for Cancer, Tianjin 300060, China. ${ }^{2}$ Department of Gastrointestinal and Pancreas Surgery, Shanxi Provincial People's Hospital, Taiyuan 030012, China. ${ }^{3}$ Department of Traditional Chinese Medicine, Shanxi Tumor Hospital, Taiyuan 030013, China. ${ }^{4}$ Physical Examination Center, First Hospital of Shanxi Medical University, Taiyuan 030001, China. ${ }^{5}$ Department of Gastrointestinal Surgery, Peking University Shougang Hospital, Beijing 100041. China. ${ }^{6}$ Department of Traditional Chinese Medicine, Shanxi Provincial People's Hospital, Taiyuan 030012, China.
Received: 15 March 2020 Accepted: 15 June 2020

Published online: 26 June 2020

\section{References}

1. Bray F, Ferlay J, Soerjomataram I, Siegel RL, Torre LA, Jemal A. Global cancer statistics 2018: GLOBOCAN estimates of incidence and mortality worldwide for 36 cancers in 185 countries. CA Cancer J Clin. 2018;68(6):394-424.

2. Sharma A, Sharma KL, Gupta A, Yadav A, Kumar A. Gallbladder cancer epidemiology, pathogenesis and molecular genetics: recent update. World J Gastroenterol. 2017;23(22):3978-98.

3. Varshney S, Butturini G, Gupta R. Incidental carcinoma of the gallbladder. Eur I Surg Oncol. 2002;28(1):4-10.

4. Goetze TO. Gallbladder carcinoma: prognostic factors and therapeutic options. World J Gastroenterol. 2015;21(43):12211-7.

5. Goetze TO, Paolucci V. Adequate extent in radical re-resection of incidental gallbladder carcinoma: analysis of the German registry. Surg Endosc. 2010; 24(9):2156-64

6. Chen Z, Gao W, Pu L, Zhang L, Han G, Zhu Q, et al. Impact of insurance status on the survival of gallbladder cancer patients. Oncotarget. 2017;8(31): 51663-74.

7. Limpawattana P, Theerakulpisut D, Wirasorn K, Sookprasert A, Khuntikeo N, Chindaprasirt J. The impact of skeletal muscle mass on survival outcome in biliary tract cancer patients. PLoS One. 2018;13(10):e0204985.

8. Schweitzer N, Kirstein MM, Kratzel AM, Mederacke YS, Fischer M, Manns MP, et al. Second line chemotherapy in biliary tract cancer: outcome and prognostic factors. Liver Int. 2019.

9. Goetze TO, Paolucci V. Influence of high-and low-volume liver surgery in gallbladder carcinoma. World J Gastroenterol. 2014;20(48):18445-51.

10. Jensen EH, Abraham A, Habermann EB, Al-Refaie WB, Vickers SM, Virnig BA, et al. A critical analysis of the surgical management of early-stage gallbladder cancer in the United States. J Gastrointest Surg. 2009;13(4):7227.

11. Wright BE, Lee CC, Iddings DM, Kavanagh M, Bilchik AJ. Management of T2 gallbladder cancer: are practice patterns consistent with national recommendations? Am J Surg. 2007:194(6):820-5 discussion 5-6.

12. Nagasue N, Yukaya H. Liver resection for hepatocellular carcinoma: results from 150 consecutive patients. Cancer Chemother Pharmacol. 1989; 23(Suppl):S78-82.

13. Fan ST, Lai EC, Lo CM, Ng IO, Wong J. Hospital mortality of major hepatectomy for hepatocellular carcinoma associated with cirrhosis. Arch Surg. 1995;130(2):198-203.

14. Kawahara R, Shirahama T, Arai S, Muroya D, Nomura Y, Fukutomi S, Shirahama N, Takagi K, Goto Y, Akashi M, Maruyama Y, Sakai H, Ishikawa H, Hisaka T, Yasunaga M, Horiuchi H, Okuda K, Akagi Y, Tanaka H. Evaluation of surgical procedures for T2 gallbladder cancer in terms of recurrence and prognosis. Kurume Med J. 2017:63(1.2):15-22.

15. Yamamoto $Y$, Sugiura $T$, Okamura $Y$, Ito $T$, Ashida R, Ohgi $K$, et al. The evaluation of the eighth edition of the AJCC/UICC staging system for intrahepatic cholangiocarcinoma: a proposal of a modified new staging system. J Gastrointest Surg. 2020;24(4):786-95.

16. Chen C, Geng Z, Shen H, Song H, Zhao Y, Zhang G, et al. Long-term outcomes and prognostic factors in advanced gallbladder cancer: focus on the advanced T stage. PLoS One. 2016;11(11):e0166361.

17. Fong $Y$, Jarnagin W, Blumgart LH. Gallbladder cancer: comparison of patients presenting initially for definitive operation with those presenting after prior noncurative intervention. Ann Surg. 2000;232(4):557-69.

18. Andren-Sandberg A. Diagnosis and management of gallbladder cancer. N Am J Med Sci. 2012;4(7):293-9.

19. Benson AB 3rd, Abrams TA, Ben-Josef E, Bloomston PM, Botha JF, Clary BM, et al. NCCN clinical practice guidelines in oncology: hepatobiliary cancers. J Natl Compr Canc Netw. 2009;7(4):350-91.

20. Maluenda F, Diaz JC, Aretxabala X, Burdiles P, Csendes A, Contreras L. Strategies for the surgical treatment of gallbladder cancer. Revista medica de Chile. 2005;133(6):723-8.

21. Wang YF, Feng FL, Zhao XH, Ye ZX, Zeng HP, Li Z, et al. Combined detection tumor markers for diagnosis and prognosis of gallbladder cancer. World J Gastroenterol. 2014;20(14):4085-92.

22. Sikora SS, Singh RK. Surgical strategies in patients with gallbladder cancer: nihilism to optimism. J Surg Oncol. 2006;93(8):670-81.

23. Lee SE, Kim SW, Han HS, Lee WJ, Yoon DS, Cho BH, Choi IS, Kim HJ, Hong SC, Lee SM, Choi DW, Park SJ, Kim HJ, Jang JY. Korean Pancreas Surgery 
Club. Surgical strategy for T2 gallbladder cancer: nationwide multicenter survey in Korea. J Korean Med Sci. 2018;33(28):e186.

24. Park TJ, Ahn KS, Kim YH, Kim TS, Hong JH, Kang KJ. The optimal surgical resection approach for T2 gallbladder carcinoma: evaluating the role of surgical extent according to the tumor location. Ann Surg Treat Res. 2018; 94(3):135-41.

25. Hueman MT, Vollmer CM Jr, Pawlik TM. Evolving treatment strategies for gallbladder cancer. Ann Surg Oncol. 2009;16(8):2101-15.

26. Onoyama H, Yamamoto M, Tseng A, Ajiki T, Saitoh Y. Extended cholecystectomy for carcinoma of the gallbladder. World J Surg. 1995;19(5): 758-63.

27. Gall FP, Kockerling F, Scheele J, Schneider C, Hohenberger W. Radical operations for carcinoma of the gallbladder: present status in Germany. World J Surg. 1991;15(3):328-36.

28. Liu F, Wang JK, Ma WJ, Yang Q, Hu HJ, Li FY. Clinical value of preoperative CA19-9 levels in evaluating resectability of gallbladder carcinoma. ANZ J Surg. 2019;89(3):E76-80.

29. Xu WY, Zhang HH, Yang XB, Bai Y, Lin JZ, Long JY, et al. Prognostic significance of combined preoperative fibrinogen and CA199 in gallbladder cancer patients. World J Gastroenterol. 2018;24(13):1451-63.

30. Cui X, Zhu S, Tao Z, Deng X, Wang Y, Gao Y, et al. Ma X Long-term outcomes and prognostic markers in gallbladder cancer. Medicine. 2018; 97(28):e11396

31. Tao Z, Li SX, Cui X, Huang Y, Zhu S, Wang Y, et al. The prognostic value of preoperative inflammatory indexes in gallbladder carcinoma with hepatic involvement. Cancer Biomark. 2018;22(3):551-7.

\section{Publisher's Note}

Springer Nature remains neutral with regard to jurisdictional claims in published maps and institutional affiliations.

Ready to submit your research? Choose BMC and benefit from:

- fast, convenient online submission

- thorough peer review by experienced researchers in your field

- rapid publication on acceptance

- support for research data, including large and complex data types

- gold Open Access which fosters wider collaboration and increased citations

- maximum visibility for your research: over $100 \mathrm{M}$ website views per year

At BMC, research is always in progress.

Learn more biomedcentral.com/submissions 